\title{
ESTUDO IMUNOLÓGICO DA ESQUISTOSSOMOSE MANSONI INIESTINAL ANTES E APÓS TRATAMENTO COM AMINONITROTIAZOL *
}

\author{
Lucyr Jones Antunes **, Dirceu Wagner Carvalho de Souza ***, Maria Suzana de \\ Lemos Souza ****, Regina Maria de Marco Turchetti*****, João Paulo Mendes \\ de Oliveira ***, Roberto Pedercini Marinho****** \\ e Ana Zélia Almendra Correia Lima $* * * * *$
}

Foram dosadas as imunoglobulinas e realizados testes cutâneos para se avaliar o sistema imunológico de pacientes portadores da forma intestinal da esquistossomose mansoni. Estes testes foram realizados antes do tratamento com aminonitrotiazol e após trinta, sessenta e noventa dias do tratamento.

Antes do tratamento o nivel de IgG (1893 $\pm 472 \mathrm{mg} \%)$ apresentava-se elevado, mas os níveis de IgA (186 $\pm 74 \mathrm{mg} \%)$ e de IgM (91 $\pm 26 \mathrm{mg} \%)$ achavam-se normais. Decorridos trinta, sessenta $e$ noventa dixs do tratamento, o nivel de IgG ciiminuiu, observando-se ligeira elevação de IgA bem como de IgM.

Os pacientes, antes do tratamento, quando testados com schistosomina $e$ anti IgE apresentaram áreas de 1,22 $\pm 0,36 \mathrm{~cm}^{2}$ e $1,04 \pm 0,25 \mathrm{~cm}^{2}$, respectivamente. Noventa dias após o tratamento, as reações à schistosomina e ao soro anti IgE produziram reaçōes com áreas ainda maiores.

O.s testes de hipersensibilidade retardada mostraram que $35 \%$ dos pacientes reagiram à schistosomina e $71 \%$ ao 2-4 dinitrofluorobenzeno.

\section{INTRODUÇÃO}

A esquistosscmose mansoni apresenta aspectos clínicos e laboratoriais diferentes de acordo com as fases e formas evolutivas da doença (4).

Em trabalhos anteriores, Antunes \& col. (1) e Hillyer (5) estudaram a concentração das imunoglobulinas no soro de pacientes portadores de diversas formas clínicas da esquistossomose mansoni, mostrando existir um aumento, estatisticamente significativo, das imunoglubulinas IgG e IgM, quando os resultados das fases aguda e crônica foram comparados.

No presente trabalho estudou-se o estado imunitário de pacientes com a forma intestinal da esquistosscmose mansoni e as alterações cobre o mecanismo imunológico destes pacientes, após o tratamento com o

* Trabolho relalizado nas Discipilnas de Doenças Infecciosas e Parasitárias e de Imunologia da Universidade Federal de Minas Gerais.

* Professor Assistente do Departamento de Bioquímica do Instituto de Ciências Biológlcas da Universidade Federal de Minas Gere is.

** Auxiliər de Ensino do Departamento de Clínica Médica da Faculdade de Medicina da Universidade Federal de Minas Gerais.

**** Auxliar de Ensino do Departomento de Medicina Preventiva e Social da Faculdade de Medicina da Universidade Federal de Minas Gerais.

***** Estagiário-Acadêmico na Disciplina de Imunologia do Instituto de Ciências Biológicas da Universidade Federal de Minas Gerais.

***** Professor Assistente do Departamento de Clínica Médica da Faculdade de Medicina da Uníersidade Federal de Minas Gerais.

Recebido para publicaçāo em 26-11-1973. 
aminonitrotiazol, fazendo-se comparação das respostas observadas nos pacientes que se curaram e nos que se mostraram resistentes à terapêutica instituída.

\section{MATERIAL E METODOS}

Seleçāo dos doentes: Foram selecionados 34 pacientes com a forma intestinal da esquistossomose mansoni.

Grupo controle: Constituído por 20 pessoas adultas não portadoras da helmintíase.

Dosagem das imunoglobulinas: Foi utilizado o método da difu:ão reversa, descrito por Antunes \& col. $(1,2)$.

Schistosomina: Obtida pela homogeinização de $500 \mathrm{mg}$ de vermes liofilizados e pela extração dos antígenos com NaC1 0,15M. A suspensão obtida, depois de desintegrada pelo ultra-som, foi centrifugada a 10.000 r.p.m., a $4^{\circ} \mathrm{C}$. Padronizou-se o sobrenadante para conter $40 \mu \mathrm{g} / \mathrm{ml}$. Ao extrato final juntou-se $0,01 \%$ de mertiolato.

Anti IgE: Utilizou-se de soro inativado de cabra imunizada com IgE humana, diluído a $1: 320$, conforme padronização descrita em trabalho de Antunes e Turchetti (3).

2-4-dinitrofluorobenzeno (DNFB, Eastman Kodack): Foram preparadas duas soluçōes em acetona nas concentrações de $10 \%$ e $0,2 \%$.

Reaçóes intradérmicas: Realizadas na face anterior do antebraço direito com $0,1 \mathrm{ml}$ de schistosomina, e na do antebraço esquerdo com $0,1 \mathrm{ml}$ de anti IgE, segundo técnica descrita por Antunes \& Turchetti. - contorno das áreas das pápulas foi delimitado e medido após 15 minutos, utilizando-se uma tela com retículos de $0,05 \mathrm{~cm}^{2}$ de área.

Sensibilidade cutânea: Procedendo-se à aplicação de $0,2 \mathrm{ml}$ da soluçāo de DNFB, a $10 \%$, na região do punho direito e reaplicação, 30 dias após, de igual volume de DNFB, a $0,2 \%$, na região do punho esquerdo. Foram considerados como reatógenos ao DNFB todos os pacientes que apresentaram, 24 a 48 horas após a segunda aplicação, reação eritematosa ou vesiculosa no local da aplicação.

Exame parasitológico das fezes: Foi utilizado o método de Hoffman, Pons \& Janer.

Tratamento especifico: $O$ aminonitrotiazol foi administrado por via oral, na dose diária de $20 \mathrm{mg} / \mathrm{kg}$ de peso corporal, em duas tomadas (após o desjejum e após - jantar), durante 10 dias consecutivos, prescrevendo-se, como coadjuvante, repouso absoluto e diazepínico.

Critérios para avaliação da eficácia terapêutica: Foram procedidas consultas mensais durante um período de seis meses, seguintes ao tratamento, nos quais se procurava obviar a cura clínica e, ainda, constatar a cura parasitológica. A cada consulta foi investigada a possibilidade de novas infecções cercarianas. Mensalmente, foram executados exames parasitológicos das fezes e hemograma de cada paciente. Nos 3 meses seguintes ao tratamento, foram feitos sorologia e testes cutâneos. Cinco meses após o tratamento, os pacientes foram submetidos à biópsia retal, realizando-se oogramas quantitativos.

\section{RESULTADOS}

Verificou-se cura em 14 pacientes, enquanto que em 5 constatou-se insucesso terapêutico; quinze pacientes foram eliminados, ou por haverem se exposto a novos contatos com águas naturais suspeitas, ou por terem faltado a alguma etapa programada para o controle após o tratamento.

Os níveis de imunoglobulinas encontrados nos 14 pacientes curados estāo registrados na Tabela I. Para os cinco pacientes que não se curaram, foram anotados os valores constantes na Tabela II.

Os testes intradérmicos de reação imediata, feitos nos pacientes curados, mostraram os resultados observados na Tabela III. Nos não curados, os referidos testes resultaram nos valores constantes da $\mathrm{Ta}$ bela IV.

O grupo considerado normal quando testado por via intradérmica com schistosomina e anti IgE, mostrou reaçōes com áreas de $0,5 \pm 0,2 \mathrm{~cm}^{2}$ e $0,81 \pm 0,32 \mathrm{~cm}^{2}$, respectivamente.

As reações de hipersensibilidade retardada à schistosomina e ao DNFB, nos pacientes curados, foram pcsitivadas em $35 \%$ e $71 \%$, respectivamente, sendo que, nos individuos normais, a hipersen sibilidade ao DNFB mostrou-se positiva em $85 \%$, não havendo reação positiva de hipersensibilidade à schistosomina.

Nos pacientes que não se curaram a positividade das reações de hipersensibilidade retardada à schistosomina e ao DNFB, foi de $20 \%$ e $60 \%$, respectivamente. 


\section{DISCUSSÃO}

Na Tabela I estão registrados os niveis de imunoglobinas, observados nos 19 pacientes tratados com aminanitrotiazol e que se apresentaram para os controles periódicos, programados dentro do período de 180 dias subsequentes ao tratamento. Consideraram-se dois grupos: $P C=14$ pacientes curados e IT $=\mathbf{5}$ pacientes em que ocorreu insucesso terapêutico.

Antes do tratamento, os grupos PC e IT apresentavam niveis elevados de IgE estatisticamente significativos, quando comparados $\mathrm{ccm}$ os valores dos individuos normais (Tabela II).

Após o tratamento houve diminuição do teor de IgG em ambos os grupos, mas seu valor, após 60 dias, já se encontrava dentro dos limites normais.

O nível de IgA nos grupos PC e IT encontrava-se abaixo dos valores normais, mas sem significado estatístico. Após o tratamento, o nivel de IgA acusou um aumento gradual até o $60^{\circ}$ dia, elevação que bem poderia ser devida à destruição dos vermes no sistema porta e nos vasos mesentéricos, com libertação de novos estímulos antigênicos em áreas ricas de células produtoras de IgA. O nivel de IgM, tanto nos individuos que se curaram quanto nos que não se curaram, apresentava-se elevado após o tratamento, fato que poderia, também, ser devido à formação de novos antigenos, a partir dos vermes lesados, com resposta imunológica do tipo reforço (booster).

Os testes intradérmicos com schistosomina, antes do tratamento, apresentavam áreas médias com $1,22 \pm 0,36 \mathrm{~cm}^{2}$ e 0,94 $\pm 0,07 \mathrm{~cm}^{2}$, respectivamente nos indivíduos curados e não curados. Estas reações acusaram ligeiro aumento nos dois grupos, mostrando, 90 dias após o início do tratamento, valores médios de $1,42 \pm 0,64 \mathrm{~cm}^{2}$ e $1,32 \pm 0,32 \mathrm{~cm}^{2}$, respectivamente nos indivíduos curados e não curados (Tabelas III e IV) .

Este aumento de reatividade à schistosomina seria uma evidência a favor da formação de novos antígenos, oriundos da lesão dos vermes pelo agente quimioterápico.

A reação de hipersensibilidade reversa, descrita por Ishizaka \& Ishizaka (6) e utilizada como um teste semiquantitativo pa- ra a medida da quantidade de IgE na pele, mostrou resultados com área de $1,04 \pm 0,25$ $\mathrm{cm}^{2}$ e $1,08 \pm 0,67 \mathrm{~cm}^{2}$, antes do tratamento, nos pacientes que se curaram e naqueles que nāo se curaram. Estes valores são um pouco superiores aos encontrados por Antunes \& col. (3), 0,81 $\pm 0,28 \mathrm{~cm}^{2}$ na população normal de Belo Horizonte, MG. $O$ valor de IgE elevou-se, em ambos os grupos de pacientes, a partir do $30^{\circ}$ dia após o tratamento, mantendo-se elevado até 90 dias após (Tabelas III e IV). Referìdos dados mostram um aumento de IgE fixado à pele, confirmando os resultados da reação com a shistosomina, de ser a IgE o anticorpo responsável pela reação imediata nos testes cutâneos.

Considerando-se o tempo de 48-72 horas para leitura da reação de hipersensibilidade retardada à schistosomina, verificou-se positividade em $35 \%$ dos pacientes que se curaram (Tabela III). Tais resultados estão próximos aos encontrados por Pellegrino e Memória (8) e por Wolfson e col. (9), que registraram $25 \%$ de reações positivas.

Procurou-se comparar, também, a capacidade sensibilizadora do DNFB em pacientes com esquistosomose mansani e em pessoas normais. Conseguiu-se induzir sensibilização ao DNFB em $71 \%$ dos pacientes que se curaram e em $60 \%$ dos que não obtiveram cura. Kligman e Epstein (7) conseguiram provocar essa sensibilização em $85 \%$ a $95 \%$ da população normal, o que corresponde aos dados que se observam em nossa população.

o presente estudo demonstrou que a resposta imunológica do tipo retardado encontra-se de certo modo deprimida, sendo esta depressão maior nos pacientes que não se curaram. E: tes dados reforçam a idéia de que os estados de hipersensibilidade humoral e celular, dos pacientes com esquistosscmose crônica,sejam fatores importantes na cura da parasitoze. Dentro desse raciocinio, os vermes, lesados pelos agentes quimirterápicos, seriam completamente destruídos pela intervenção do mecanismo imunológico, responsável pela defesa do hospedeiro. Ter-se-ia, assim, uma possivel explicação porque os agentes quimioterápicos não curam $100 \%$ dos pacientes.

Os Autores estão concluindo investigacāo em torno dos mesmos processos imunitários, face ao comportamento decorrente 
TABELA I - Nívais das imunoglobulinas observados em pacientes com esquistossomose mansoni intestinal, antes e após a cura obtida com tratamento pelo aminonitrotriazol

\begin{tabular}{|c|c|c|c|c|}
\hline \multirow{3}{*}{$\begin{array}{l}\text { IMUNOGLO- } \\
\text { BULINAS } \\
(\mathrm{em} \mathrm{mg \% )}\end{array}$} & \multicolumn{4}{|c|}{ TRATAMENTO } \\
\hline & \multirow{2}{*}{ Antes } & \multicolumn{3}{|c|}{ Uepois } \\
\hline & & 30 dias & 60 dias & 90 dias \\
\hline IgG & $1893 \pm 472$ & $1639 \pm 429$ & $1255 \pm 577$ & $1266 \pm 389$ \\
\hline $\operatorname{IgA}$ & $186 \pm 74$ & $146 \pm 55$ & $258 \pm 130$ & $270 \pm 98$ \\
\hline IgM & $91 \pm 26$ & $92 \pm$ & $108 \pm 33$ & $111 \pm 31$ \\
\hline
\end{tabular}

TABELA II - Niveis das imunoglobulinas cbservados em pacientes ccm esquistossomose manscni intestinal, antes e após o in ucesso terapêutico verificado com o uso de aminonitrotiazol

\begin{tabular}{l|r|r|r|r}
\hline \multirow{2}{*}{$\begin{array}{c}\text { IMUNOGLO- } \\
\text { BULINAS } \\
(\mathrm{em} \mathrm{mg \% )}\end{array}$} & \multicolumn{5}{|c}{ TRATAMENTO } \\
\cline { 2 - 5 } & Antes & \multicolumn{3}{|c}{ Depois } \\
\cline { 2 - 5 } & & 30 dias & 60 dias & 90 dias \\
\hline IgG & $2070 \pm 551$ & $1300 \pm 243$ & $1018 \pm 69$ & $1249 \pm 434$ \\
IgA & $168 \pm 67$ & $178 \pm 130$ & $211 \pm 115$ & $318 \pm 65$ \\
IgM & $105 \pm 19$ & $76 \pm 23$ & $142 \pm 72$ & $102 \pm 44$ \\
\hline
\end{tabular}

TABELA III - Resultados dos testes intradérmicos, de reação imediata, observados em pacientes $\mathrm{ccm}$ esquistossomose manscni intestinal, antes e após a cura obtida com tratamento pelc amincnitrotiazol

\begin{tabular}{l|c|c|c|c}
\hline \multirow{2}{*}{$\begin{array}{c}\text { TESTES IN- } \\
\text { TRATERMICOS } \\
\left(\mathrm{em} \mathrm{cm}^{2}\right)\end{array}$} & Antes & \multicolumn{3}{|c|}{ TRATAMENTO } \\
\cline { 2 - 4 } & & 30 dias & 60 dias & 90 dias \\
\hline Schi-tosomina & $1,22 \pm 0,36$ & $1,23 \pm 0,44$ & $1,77 \pm 0,42$ & $1,42 \pm 0,64$ \\
Anti IgE & $1,04 \pm 0,25$ & $1,16 \pm 0,37$ & $1,08 \pm 0,31$ & $1,15 \pm n, 32$ \\
\hline
\end{tabular}

TABELA IV - Resultados dos testes intradérmicos, de reação imediata, observados em pacientes com esquistossomose mansoni intestinal, antes e após o insucesso terapêut:co verificado $\mathrm{ccm}$ o uso de aminonitrotiazol

\begin{tabular}{l|c|c|c|c}
\hline \multirow{2}{*}{$\begin{array}{c}\text { TESTES IN- } \\
\text { TRATERMICOS } \\
\left(\mathrm{em} \mathrm{cm}^{2}\right)\end{array}$} & Antes & TRATAMENTO \\
\cline { 2 - 4 } & & 30 dias & 60 dias & 90 dias \\
\hline Schistosomina & $0,94 \pm 0,07$ & $1,28 \pm 0,46$ & $1,28 \pm n, 46$ & $1,32 \pm 0,32$ \\
Anti IgE & $1,08 \pm 0,67$ & $1,14 \pm \mathbf{0 , 3 2}$ & $1,14 \pm 0,32$ & $1,32 \pm 0,32$ \\
\hline
\end{tabular}


do uso de outro quimioterápico disponivel para o tratamento da helmintiase. Já iniciaram, também, outros trabalhos visando à análise do mecanismo intimo da respos- ta imunológica, em pacientes portadores da forma hepatcesplênica e naqueles que se encontrem na fase inicial da esquistossomose mansoni.

\section{SUMMARY}

The amount of immunoglobulins serum and the cutaneous sensitivity to specific antigen in 19 patients with intestimal schistosomiasis were determined, as an attempt to study the incidence of delayed and imediate type of hypersensitivity. The tests were performed before and thirty, sixty and ninety days after treatment with aminonitrotiazol.

The immunoglobulin levels before treatment were found to be $1,893 \pm 472$, $186 \pm 74$ and $91 \pm 26 \mathrm{mg} \%$, respectively for $\mathrm{IgG}, \mathrm{IgA}$ and $\mathrm{Ig} M$; ninety days after treatment the level for IgG became normal $(1,266 \pm 389 \mathrm{mg} \%)$ and a slight increase of $\operatorname{IgA}(270 \pm 89 \mathrm{mg} \%)$ and $\operatorname{IgM}(111 \pm 31 \mathrm{mg} \%)$ was observed.

The patients were intradermally tested with schistosomin and with anti IgE serum. The tests before treatment gave the following results: $1.22 \pm 0.36 \mathrm{~cm}^{2}$ for schistosomin and $1.04 \pm 0.25 \mathrm{~cm}^{2}$ for anti IgE. Ninety days afterwards a slight increase of the reactions was observed and the results respectively were $1.42 \pm 0.65 \mathrm{~cm}^{2}$ and $1.15 \pm 0.32 \mathrm{~cm}^{2}$.

The studies for dislayed hypersenstivity indicated that $35 \%$ of patients showed an area of induration larger than $0.5 \mathrm{~cm}^{2}, 48$ hours after the intradermal injection with schistosomin, and $71 \%$ developed positive reaction when challenged with dinitrofluorobenzene.

\section{REFERÊNCIAS BIBLIOGRÃFICAS}

1. ANTUNES, L. J.: REIS, A. P.; PELEGRINO, J.; TAVARES, C. A. P. \& KATZ, N. - Immunoglobulins in human schistosomiasis. J. Parasit., 57: 539-542, 1971 .

2. ANTUNES, L. J.; REIS, A. P.; TAVARES, C. A. P. \& PELEGRINO, J. Dozagem das imunoglobulinas e reação de hemaglutinação passiva $\mathrm{em}$ pacientes com leishmaniose cutâneomucosa. Rev. Inst. Med. Trop., São Paulo, 14: 203-206, 1972

3. ANTUNES, L. J. \& TURCHETTI, R. M. M. - Reverse hypersensibility reaginic A semiquantitation of IgE level in normal subjects and in patients with allergy to house dust. Rev. Bras. Pesq. Med. e Biol, São Paulo, 5: 212213,1973

4. CUNHA, A. S. - Esquistossomose Mansoni. Sarvier. Editora da Universidade de São Paulo, São Paulo, 1970.
5. HILLYER, G. - Immunoprecipitins in Schistosoma mansoni infections. Exper. Parasit. 25: 37-381, 1969.

6. ISHIZAKA, K. \& ISHIZAKA, T. - Reversed type allergic skin reactions by anti IgE globulins antibodies in human and monkeys. J. Immunol. 100: 554-562, 1968.

7. KLIGMAN, A M. \& EPSTEIN, W. L Scmo factors affecting contact sensitization in man. Mechanism of hypersensitivity. In J. H. Schaffer, G. A. Lo Grippo, M. W. Chase. Boston, Little, Brown \& Company, 1959.

8. PELEGRINO, J. \& MEMORIA, J. M. P. - The skin test in schistosomiasis mansoni. V. Delayed type of cutaneous response. Rev. Inst. Med. trop., São Paulo, 2: 265-267, 1960

9. WOLFSON, R. L.; HORNER, D. W. \& KAGEN, I. G. - Delayed skin sensitivity in schisto:omiasis. J. Parasitol. 55: $1174-1179,1969$. 